\title{
Multi-period Survey Forecasts Of Business Investment: Is There Room for Improvement?
}

Hamid Baghestani, University of Colorado, Boulder

Woo Jung, (woo.jung@colorado.edu)., University of Colorado, Denver

\begin{abstract}
The ASA-NBER multiperiod survey forecasts of business investment are compared with univariate forecasts to assess predictive information content. In general, the survey forecasts fail to be unbiased, and, none fully exploit the information in the past history of business investment. Interestingly, however, they contain predictive information on other relevant (quantitative or qualitative) variables. Combined forecasts of survey and univariate models score significant improvements over either, suggesting their potential usefulness in policy-making.
\end{abstract}

\section{Introduction}

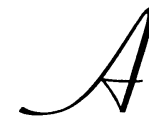

a volatile component of aggregate demand, business investment has been considered an important source of fluctuations in output and employment. In recent years, a number of proposals, including the adoption of tax incentives, have been put forth to combat the apparent slowdown in the growth of capital investment by businesses since 1980. Effective policy actions require multiperiod forecasts with strong predictive information content. An important source of information on the future course of business investment is provided by the quarterly survey of professional forecasters originally conducted by the National Bureau of Economic Research in cooperation with the American Statistical Association (ASA-NBER) and currently by the Federal Reserve Bank of Philadelphia. Since 1981.3, the survey participants have supplied the nonoverlapping forecasts of the real nonresidential or business investment, among other target variables, for the survey

Readers with comments or questions are encouraged to contact the authors via e-mail. quarter as well as the following four quarters.

It is often argued that survey-based forecasts, unlike econometric ones, have the flexibility of incorporating relevant qualitative market information. The purpose of this paper is first to utilize comparable univariate forecasts to assess the predictive information content of the ASA-NBER multiperiod survey forecasts of business investment and then to investigate ways to improve the forecastability of such spending. Univariate modeling is accepted in the literature as a useful benchmark against which survey or other more complicated forecasting models can be judged. Such a usefulness is especially the case in this study, since, consistent with Kopcke's (1993) observation, the historical trends and cyclical dynamics of business investment are sufficiently stable to reasonably explain the future course of such spending. Specifically, the generated univariate forecasts, which efficiently utilize the information in the past history of the target variable, are shown to be unbiased and hence defined as a "weakly rational" measure of 
business investment expectations (Pearce, 1979). Compared with these rational measures, the survey forecasts, while containing information on some other relevant variables, fail to fully include the information in the past history of business investment, leaving room for improvement. Utilizing the method suggested by Granger and Ramanathan (1984), the survey and univariate forecasts are then combined, which produces superior forecasts both within and out of sample, suggesting their potential usefulness in policy making.

The format of this paper is follows: Section II first describes the ASA-NBER data in some detail and then explains how the univariate forecasts are generated. Section III investigates the unbiasedness and predictive information content of the survey forecasts. Section IV evaluates the relative forecasting performance of the combined survey and univariate forecasts. Section V concludes the paper, and Section VI makes some suggestions for future research.

\section{Survey and Comparable Univariate Fore- casts}

The ASA-NBER quarterly survey, started in 1968, initially sought to collect multiperiod forecasts of ten U.S. macroeconomic variables. Beginning with the third quarter of 1981, the survey also added the real nonresidential or business investment as another target variable. ${ }^{1}$ The goal has been to obtain the nonoverlapping forecasts for the current (survey) quarter and the following four quarters. The survey questionnaire is sent out sometime at the end of the first month of the quarter, and the participants are asked to mail back the completed questionnaire by the middle of the second month.

Along with the questionnaire, the participants are provided with the previous quarter's preliminary data of each target variable announced 15 days after the end of the quarter and published, for the respective quarters, in the April, July, October, and January issues of the Business Conditions Digest $(B C D)$ and Survey of Current Business $(S C B)$.
Zarnowitz (1985) studies the rationality of the ASA-NBER forecasts of nominal and real GNP, implicit price deflator, unemployment rate, consumer expenditures and the change in nominal business inventories for 1968:4-1979:1. $\mathrm{He}$ first examines the individual forecasts in a pooled time-series cross-section regression and then the sample mean response of the individual forecasts in a time-series regression. Comparing the findings, Zarnowitz concludes that the sample mean forecasts generally tend to be more supportive of the expectational rationality. He argues that "because in each unit period there is only one actual value but many individual predictions for any target variable, pooled regressions yield biased estimates of the parameters. They result in unreliable tests that greatly overstate the extent of bias in the forecasts" (Zarnowitz, 1985, p. 308). Accordingly, we utilize the sample median response of the individual forecasts, as reported by the source, to test the rationality of the multiperiod survey forecasts of business investment.

Another issue at hand is how to measure the actual series with which the forecasts are compared. Zarnowitz utilizes the final available revised series. Keane and Runkle (1990), who examine the rationality of the one-quarter-ahead survey forecast of the implicit price deflator, utilize the first-revised data. Hafer and Hein (1985), who study the accuracy of the currentquarter survey forecast of the implicit price deflator, and Baghestani and Kianian (1993), who investigate the rationality of survey forecasts on 15 target variables for 1981:3-1991:2, utilize the preliminary data announced 15 days after the end of the quarter. In this study, we follow Keane and Runkle and measure the actual series of business investment by the first-revised data announced 45 days after the end of the quarter and published, for the respective quarters, in the May, August, November, and February issues of $B C D$ and $S C B$. The use of the first-revised instead of the final available revised data is easier to justify, since the nature of the subsequent data revisions is difficult to predict at the time of survey. On the other hand, the use of preliminary 
data is avoided, since the survey participants are expected to do more than just forecasting the preliminary data.

The univariate model of business investment used here is an integrated autoregressive process with the following estimates using the 1962:1-1981:2 sample information available in the 1981 July issues of $B C D$ and $S C B$,

$$
\begin{aligned}
& \left(1-0.301 \mathrm{~B}^{1}-0.186 \mathrm{~B}^{2}+0.423 \mathrm{~B}^{8}\right)(1-\mathrm{B}) \mathrm{I}=0.011 \\
& \text { (2.70) (1.68) (4.11) } \\
& \mathrm{R}^{2}=0.424 \quad \mathrm{Q}[12]=3.04
\end{aligned}
$$

where It is the logarithm of the real nonresidential or business investment (NIPA definition, series no. 86 in $B C D$ ) with the last observation measured by the preliminary data released 15 days after the end of quarter; ${ }^{2} \mathrm{~B}$ is the backward shift operator; Q[12] is the Ljung-Box Q-statistic with 12 degrees of freedom; and absolute tvalues are in parentheses. The included autoregressive parameter estimates are significantly different from zero, and the Q-statistic is considerably below the $10 \%$ critical value, 18.55 , indicating that the residuals are white noise, and thus the model is correctly specified. Business investment is found to be integrated of order of one, and therefore, is differenced once to achieve stationarity. ${ }^{3}$ To increase the efficiency of our estimates, the third through seventh autoregressive orders, which have insignificant t-ratios, are excluded.

The 1962:1-1981:2 parameter estimates in (1) are used to generate the ex ante forecasts of business investment for the following five quarters of 1981:3 through 1982:3. The 1981:3 univariate forecast matches the current-quarter survey forecast. The 1981:4, 1982:1, 1982:2, and 1982:3 univariate forecasts match, respectively, the one-, two-, three-, and four-quarterahead survey forecasts made in the first half of the 1981:3 survey quarter. Re-estimating the model for 1962:1-1981:3, the updated parameter estimates are then used in the same manner to generate the ex ante forecasts for 1981:4 through 1982:4. This procedure is repeated until the last set of forecasts for 1995:2 through 1996:2 is generated based on the 1962:1-1995:1 sample information. For compatibility with the survey, the univariate model utilizes the data on business investment most recently available at the time of survey from the monthly issues of $B C D$ and $S C B$.

\section{Testing for Unbiasedness and Predictive Information Content}

The unbiasedness of forecasts is examined by estimating

$\mathrm{It}+\mathrm{f}-\mathrm{It}-2=\alpha 0+\alpha 1\left(\hat{\mathrm{I}}_{\mathrm{t}+\mathrm{f}}-\mathrm{I} \mathrm{t}-2\right)+\mathrm{ut+f}$

$\mathrm{f}=0,1,2, \ldots, 4$

where It+f is the first-revised observed value of business investment in $t+f$, while $\hat{\mathrm{I}}_{\mathrm{t}+\mathrm{f}}$ is the forecast of $\mathrm{It}+\mathrm{f}$ at quarter $\mathrm{t}$ with $\mathrm{f}$ as the forecast horizon (all variables are in logarithms). Since the first-revised value is released 45 days after the end of the quarter, It-2 is the latest firstrevised value of business investment available at the time of survey. ${ }^{4}$ Following Fair and Shiller $(1989,1990)$, the most recently observed value at the time of forecast, It-2, is subtracted from both $\mathrm{I} t+\mathrm{f}$ and $\hat{\mathrm{I}}_{\mathrm{t}+\mathrm{f}}$ to avoid problems due to the nonstationarity of business investment. The forecast fails to be unbiased if the null hypotheses $\mathrm{H} 0: \alpha 0$ $=0$ and $\alpha_{1}=1$ are individually and/or jointly rejected.

To compare the predictive information in the survey forecast, $\hat{\mathrm{I}}_{\mathrm{t}+\mathrm{f}}^{(\mathrm{s})}$, with the univariate

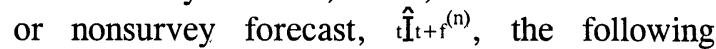
equation is estimated:

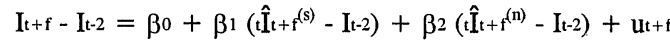

$\mathrm{f}=0,1, \ldots, 4$

where significant $\hat{\beta}{ }_{1}$ with insignificant $\hat{\beta}{ }_{2}$ implies that the survey forecast includes more predictive information than that contained in the univariate forecast; the converse is also true. Each forecast includes distinct information, if $\hat{\beta}_{1}$ and $\hat{\beta{ }_{2}}$ are both significant. Insignificant $\hat{\beta}_{1}$ and $\hat{\beta}_{2}$, further, implies that each forecast contains similar information. 
In estimating (2) and (3), the OLS parameter estimates are still consistent, but the OLS covariance matrix estimates prove to be inconsistent due to the inherent serial correlation and heteroskedasticity in the forecast errors. For instance, when making the current-quarter forecast, the forecast errors for the quarter prior to the survey quarter is not yet known and thus is not part of the available information set (note that the first-revised data are not available until 45 days after the end of the quarter when the survey forecasts are already made.) The possibility that $\mathrm{ut}$ is correlated with $\mathrm{ut-1}$, therefore, cannot be ruled out, leading us to postulate a 1st-order moving average process for the current-quarter forecast error, ut, under the null hypothesis of rationality. When making the one-quarter-ahead forecast, the forecast error for the quarter prior to the survey quarter as well as the forecast error for the survey quarter are not yet known and thus are not part of the available information set. The possibility that $\mathrm{ut}_{\mathrm{t}+1}$ is correlated with $\mathrm{ut}$ and $\mathrm{ut}-1$, therefore, cannot be ruled out, leading us to postulate a 2nd-order moving average process for the one-quarter-ahead forecast error, $\mathrm{u}_{\mathrm{t}+1}$, under the null hypothesis of rationality. Accordingly, we may express the serial correlation as

$$
\begin{aligned}
& u_{t+f}=\varepsilon^{t+f}+\sum_{j=1}^{f+1} \rho j \varepsilon^{t+f-j} \\
& f=0,1, \ldots, 4
\end{aligned}
$$

It is important to note that serial corre-

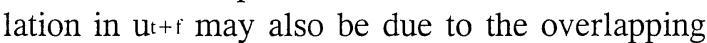
problem created by subtracting from both sides of (2) and (3) the most recently observed value of business investment, It-2.

Another point to keep in mind is that forecast errors are generally heteroskedastic. This is especially true with the survey forecasts where the number of respondents over whom the medians are taken varies from time to time. ${ }^{5}$ To account for the possibility of heteroskedasticity and serial correlation in forecast errors, the correct covariance matrix is estimated based on the procedure described below.
Consider the following general model

$\mathrm{Y}=\mathrm{X} \beta+\mathrm{u}$

where $\mathrm{Y}$ is the (Tx1) vector of observations on the dependent variable, $\mathrm{X}$ is the (Txk) matrix of observations on $\mathrm{k}$ explanatory variables, and $\mathrm{u}$ is the $(\mathrm{Tx} 1)$ vector of disturbances. Let $\beta^{\wedge}$ be the OLS estimator of $\beta$, then the covariance matrix of $\hat{\beta}, \mathrm{V}\left(\beta^{\wedge}\right)$, is estimated as:

$\mathrm{V}\left(\beta^{\wedge}\right)=\left(\mathrm{X}^{\prime} \mathrm{X}\right)^{-1} \mathrm{~S}\left(\mathrm{X}^{\prime} \mathrm{X}\right)^{-1}$

where

$S=\Omega 0+\sum_{j=1}^{f+1}\left(\Omega j+\Omega j^{\prime}\right)$

In accounting for the heteroskedasticity, following White (1980),

$\Omega 0=\sum_{t=1}^{T} \hat{u}^{2} t+f X^{\prime} t+f X_{t+f}$

and in accounting for the serial correlation, following Fair and Shiller,

$\Omega j=\sum_{t=j+1}^{T}\left(\hat{u}_{t+f}\right)\left(\hat{u}_{t+f-j}\right) X^{\prime} t+f X_{t+f-j}$

$\mathrm{j}=0,1, \ldots, \mathrm{f}$

Note that $\hat{u}_{t+\mathrm{f}}$ is the OLS residual at Row $\mathrm{t}+\mathrm{f}$ of vector $\hat{\mathrm{u}}$, and $\mathrm{X}_{\mathrm{t}+\mathrm{f}}$ is the row $\mathrm{t}+\mathrm{f}$ values of ma-

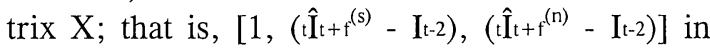
equation 3. This procedure allows us to calculate the correct standard errors of the OLS parameter estimates as well as the following statistic for testing the joint null hypothesis that $\beta=\beta^{0}$,

$q=\left(\beta^{\wedge}-\beta^{0}\right)^{\prime} X^{\prime} X S^{-1} X^{\prime} X\left(\beta^{\wedge}-\beta^{0}\right)$

which will follow $\left.\chi^{\left(^{2}\right.} \mathrm{k}\right)$ under the null hypothesis and is expected to be significantly large under the alternative hypothesis.

The OLS parameter estimates of (2) with the correct covariance matrix estimates for the survey and univariate forecasts are reported in Table 1. As seen, the multiperiod univariate forecasts are all unbiased, since the null hypothe- 
Table 1

Tests of unbiasedness of business investment forecasts: $t=1981: 3-1995: 2$

Equation (2): $\mathrm{It}+\mathrm{f}-\mathrm{It}-2=\alpha^{0}+\alpha_{1}\left(\hat{\mathrm{t}}_{\mathrm{t}+\mathrm{f}}-\mathrm{I} \mathrm{t}-2\right)+\mathrm{u} t+\mathrm{f}$

\begin{tabular}{lllll} 
Model & $\alpha_{0}$ & $\alpha_{1}$ & SE & $\chi^{2^{2}}$ \\
\hline
\end{tabular}

Current quarter forecast $(\mathrm{f}=0) ; 1981: 3-1995: 2$ sample forecast

$\begin{array}{lllll}\text { Survey } & 0.009^{\mathrm{b}} & 1.001^{\mathrm{a}} & 0.0246 & 5.78^{\mathrm{c}} \\ & (.0041) & (.0940) & & \\ \text { Univariate } & 0.007 & 0.907^{\mathrm{a}} & 0.0259 & 3.15\end{array}$

(.0044) (.0933)

One-Quarter-Ahead Forecast ( $\mathrm{f}=1) ; 1981: 4-1995: 3$ sample forecast

$\begin{array}{lllll}\text { Survey } & 0.015^{\mathrm{c}} & 1.069^{\mathrm{a}} & 0.0382 & 3.60 \\ \text { Univariate } & (.0089) & (.129 .5) & & \\ & 0.009 & 0.938^{\mathrm{a}} & 0.0387 & 2.78\end{array}$

Two-Quarter-Ahead Forecast ( $\mathrm{f}=2)$; 1982:1-1995:4 sample forecast

$\begin{array}{lllll}\text { Survey } & 0.014 & 1.179^{\mathrm{a}} & 0.0492 & 3.72 \\ & (.0151) & (.1576) & & \\ \text { Univariate } & 0.014 & 0.923^{\mathrm{a}} & 0.0529 & 1.35\end{array}$

Three-Quarter-Ahead Forecast (f=3); 1982:2-1996:1 sample forecast

$\begin{array}{lllll}\text { Survey } & 0.013 & 1.252^{\mathrm{a}} & 0.0612 & 4.73^{\mathrm{c}} \\ & (.0219) & (.1780) & & \\ \text { Univariate } & 0.019 & 0.906^{\mathrm{a}} & 0.0669 & 1.11 \\ & (.0192) & (.1456) & & \end{array}$

Four-Quarter-Ahead Forecasts $(f=4) ; 1982: 3-1996: 2$ sample forecast

$\begin{array}{lllll}\text { Survey } & 0.011 & 1.315^{\mathrm{a}, \mathrm{d}} & 0.0738 & 5.00^{\mathrm{c}} \\ & (.0256) & (.1829) & & \\ \text { Univariate } & 0.027 & 0.844^{\mathrm{a}} & 0.0816 & 1.43 \\ & (.0258) & (.1745) & & \end{array}$

Notes: Survey is the ASA-NBER survey model, and univariate is the integrated autoregressive model in (1). $I t+f$ is the logarithm of the first-revised realized value of real nonresidential or business investment in $\mathrm{t}+\mathrm{f}$, and $\mathrm{t} \hat{\mathrm{I}}_{\mathrm{t}+\mathrm{f}}$ is the forecast made in quarter $\mathrm{t}$ and relating to quarter $t+f$ with $f$ as the forecast horizon. It-2 is the logarithm of the first-revised value of business investment most recently available at the time of survey. $\chi^{2^{2}}$ is the chi-square statistic for testing the joint null hypothesis of unbiasedness. SE is the standard error of regression. The numbers in parentheses are the standard errors of parameter estimates. Significance is indicated by a $(1 \%)$, b $(5 \%)$, c $(10 \%)$. $\mathrm{d}$ indicates $\alpha_{1}$ is different from one at the $10 \%$ or lower level of significance. ses $\mathrm{H}_{0}: \alpha_{0}=0$ and $\mathrm{H}_{0}: \alpha_{1}=1$ cannot be individually or jointly rejected at the $10 \%$ or lower level of significance. Accordingly, these unbiased and efficient univariate forecasts are taken as the "weakly rational" measures of business investment expectations.

The results of unbiasedness for the survey forecasts, however, are mixed. The current quarter and the one-quarter-ahead survey forecasts, for example, fail to be unbiased due to systematic underpredictions; that is, while the null hypothesis $\mathrm{H}_{0}: \alpha 1=1$ cannot be rejected, the null hypothesis $\mathrm{H}_{0}: \alpha 0=0$ is rejected at the $10 \%$ (or lower) level of significance.

The two- quarter-ahead survey forecast, however, passes the criterion of unbiasedness, since the null hypotheses $\mathrm{H}_{0}: \alpha 0=0$ and $\mathrm{H}_{0}: \alpha_{1}=1$ cannot be individually or jointly rejected. The three and four-quarter-ahead forecasts again fail to be unbiased, since the joint null hypothesis $\mathrm{H} 0$ : $\alpha 0=0$ and $H_{0}: \alpha_{1}=1$ is rejected at the $10 \%$ level of significance. ${ }^{6}$

To investigate the predictive information content of the survey forecasts, Table 2 reports the OLS parameter estimates of equation (3) with the correct covariance matrix estimates. For the current-quarter and three-, and four-quarter-ahead, we reject the null hypothesis $\mathrm{H}_{0}: \quad \beta_{1}=0$.

However, we cannot reject the null hypothesis $\mathrm{H}_{0}$ : $\beta_{2}=0$ at any reasonable level of significance. This suggests that the survey forecasts are dominant and fully contain the information in the past history of business investment. 
Table 2

Alternative forecast accuracy: $t=1981: 3-1995: 2$

Equation (3): It+f $-I_{t-2}=\beta 0+\beta 1\left(\hat{t}_{t}+f^{(s)}-I_{t-2}\right)+\beta 2\left(\hat{I}_{t+f^{(n)}}-I_{t-2}\right)+u_{t+f}$

\begin{tabular}{|c|c|c|c|c|c|}
\hline Forecast period & $\mathrm{f}$ & $\beta 0$ & $\beta_{1}$ & $\beta 2$ & SE \\
\hline $1981: 3-1995: 2$ & 0 & $0.008^{c}$ & $\begin{array}{l}0.702^{\mathrm{a}} \\
(.0043)\end{array}$ & $\begin{array}{l}0.305 \\
(.2757)\end{array}$ & $\begin{array}{c}0.0244 \\
(.2716)\end{array}$ \\
\hline $1981: 4-1995: 3$ & 1 & 0.010 & $\begin{array}{l}0.607^{\mathrm{a}} \\
(.0071)\end{array}$ & $\begin{array}{l}0.481^{\mathrm{a}} \\
(.1731)\end{array}$ & $\begin{array}{l}0.0365 \\
(.1714)\end{array}$ \\
\hline $1982: 1-1995: 4$ & 2 & 0.009 & $\begin{array}{l}0.812^{\mathrm{a}} \\
(.0136)\end{array}$ & $\begin{array}{l}0.388^{\mathrm{b}} \\
(.2464)\end{array}$ & $\begin{array}{c}0.0477 \\
(.2031)\end{array}$ \\
\hline 1982:2-1996:1 & 3 & 0.009 & $\begin{array}{l}0.919^{\mathrm{a}} \\
(.0204)\end{array}$ & $\begin{array}{l}0.353 \\
(.3501)\end{array}$ & $\begin{array}{l}0.0600 \\
(.2505)\end{array}$ \\
\hline $1982: 3-1996: 2$ & 4 & 0.008 & $\begin{array}{l}1.058^{\mathrm{a}} \\
(.0250)\end{array}$ & $\begin{array}{l}0.264 \\
(.4591)\end{array}$ & $\begin{array}{c}0.0734 \\
(.3057)\end{array}$ \\
\hline
\end{tabular}

Notes: $\hat{\mathrm{t}}_{\mathrm{t}+\mathrm{f}^{(\mathrm{s})}}$ and $\hat{\mathrm{t}}_{\mathrm{t}}+\mathrm{f}^{(\mathrm{n})}$ are, respectively, the survey and univariate forecasts in logarithms.

The addition of the univariate forecasts through combination, therefore, should not lead to any higher predictive performance already achieved by the survey forecasts at the forecast horizon $\mathrm{f}$ $=0,3$, and 4 .

For the one- and two-quarter-ahead, the null hypotheses $\mathrm{H}_{0}: \beta_{1}=0$ and $\mathrm{H}_{0}: \beta_{2}=0$ are both rejected. This indicates that the survey forecasts do not completely dominate the univariate forecasts or fail to fully contain the information in the past history of business investment. Accordingly, it is argued that the one- and twoquarter-ahead survey and univariate forecasts each contain distinct information and possess complementary statistical attractiveness, which upon combination, should lead to a higher predictive performance. Therefore, in what follows, we examine the additional accuracy of the combined survey-univariate forecasts at the oneand two-quarter horizons.

\section{Combining Survey and Univariate Fore- casts}

In order to obtain the combining weights, we regress the actual values against the alternative forecasts; that is, estimating equation (3). This method is preferred to an alternative method that excludes the constant term from equation (3). Granger and Ramanathan (1984, p. 201) argue that the former method is more appropriate because it produces an unbiased combined forecast even if individual forecasts are biased. The weights are not constrained to add to unity, since Granger and Ramanathan (1984) also demonstrate that the common practice of obtaining a weighted average of forecasts is inferior and should be abandoned.

We analyze the combined forecasts in two ways.

First, the combining weights are determined using the entire forecast series to evaluate the relative forecasting performance within sample. Second, starting with a subset of forecast series, the weights are generated recursively to evaluate the relative forecasting performance out of sample. For example, we begin by calculating the weights using the 1981.31989.4 forecast series and then generate the combined one- and two-quarter-ahead forecasts made in 1990.1. The weights are recalculated using the 1981.3-1990.1 forecast series to obtain the combined forecasts made in 1990.2. This procedure is repeated until the last set of combined forecasts for 1995.2 are obtained based on the weights calculated using the 1981.3-1995.1 forecast series.

Columns 1 and 2 of Table 3 report the combining weights and evaluation for the oneand two-quarter-ahead forecasts in terms of the mean percent error (\%ME) and root mean squared percent error (\%RMSE) for the withinsample exercise. The original models indicate that the extent of underprediction is more serious for the survey than the univariate model which produces considerably lower mean error. However, for the one-quarter-ahead, the univariate forecast has a smaller root mean squared error, while, for the two-quarter-ahead forecast, the 


\begin{tabular}{|c|c|c|c|c|c|c|c|c|}
\hline \multirow[b]{4}{*}{ Models } & \multicolumn{8}{|c|}{$\begin{array}{c}\text { Table } 3 \\
\text { Original vs. combined forecast errors: } t=1981: 3-1995: 2\end{array}$} \\
\hline & \multicolumn{4}{|c|}{ Within sample results } & \multicolumn{4}{|c|}{ Out of sample results } \\
\hline & \multicolumn{2}{|c|}{ 1-Qtr-ahead } & \multicolumn{2}{|c|}{ 2-Qtr-ahead } & \multicolumn{2}{|c|}{ 1-Qtr-ahead } & \multicolumn{2}{|c|}{ 2-Qtr-ahead } \\
\hline & $\% \mathrm{ME}$ & \%RMSE & $\% \mathrm{ME}$ & \% RMSE & $\% \mathrm{ME}$ & $\%$ RMSE & $\% \mathrm{ME}$ & $\%$ RMSE \\
\hline \multicolumn{9}{|l|}{ Original } \\
\hline Survey & 1.64 & 4.10 & 2.00 & 5.29 & 2.14 & 4.00 & 2.59 & 4.83 \\
\hline Univariate & 0.75 & 3.88 & 1.04 & 5.32 & 1.22 & 3.91 & 1.95 & 5.50 \\
\hline \multicolumn{9}{|l|}{ Combined } \\
\hline \multirow[t]{2}{*}{ Survey \& Univariate } & 0.00 & 3.55 & 0.00 & 4.63 & 0.83 & 3.54 & 1.01 & 4.38 \\
\hline & \multicolumn{4}{|c|}{ Weights for combined model } & \multicolumn{4}{|c|}{$\begin{array}{l}\text { Mean weights for combined } \\
\text { methods A \& B }\end{array}$} \\
\hline Survey & \multicolumn{2}{|c|}{0.610} & \multicolumn{2}{|c|}{0.810} & 0.5 & & \multicolumn{2}{|c|}{0.570} \\
\hline Univariate & \multicolumn{2}{|c|}{0.480} & \multicolumn{2}{|c|}{0.390} & 0.5 & & \multicolumn{2}{|c|}{0.490} \\
\hline Constant & \multicolumn{2}{|c|}{0.010} & \multicolumn{2}{|c|}{0.009} & 0.0 & & \multicolumn{2}{|c|}{0.007} \\
\hline \multicolumn{9}{|c|}{$\begin{array}{l}\text { Notes: \%ME is the mean percent error, and \%RMSE is the root mean squared error. For the within sample, } \\
\text { the forecast periods for the one- and two-quarter-ahead are the same as those reported in Tables } 1 \text { and } 2 \text {. For } \\
\text { the out of sample results, the forecast periods for the one and two-quarter-ahead forecasts are, respectively, } \\
1990.2-1995.3 \text { and } 1990.3-1995.4 \text {. }\end{array}$} \\
\hline
\end{tabular}

survey has a smaller root mean squared error. Combining the two produces improvements over either of the original forecasts. Such improvements are especially noteworthy in terms of mean error. Similar conclusion holds when comparing the forecasts in terms of root mean squared errors.

Columns 3 and 4 of Table 3 reports the average value of the recursively generated weights and evaluation for the out of sample exercise. As for the within-sample exercise, the extent of underprediction is more serious for the survey than the univariate model with considerably lower mean error. Again, for the onequarter-ahead, the univariate forecast has a smaller root mean squared error, while, for the two-quarter-ahead forecast, the survey has a smaller root mean squared error. Combination generates combined forecasts that are consistently superior to the original survey and univari- ate forecasts. This superiority is more evident in terms of mean errors.

\section{Conclusion}

The within and out of sample evaluations certainly support the argument that the survey and univariate forecasts each contain distinct information, which upon combination, lead to a higher predictive performance. This implies that one should not dismiss survey forecasts when they fail to be unbiased and/or efficient. Given the possibility that the survey forecasts may contain useful qualitative information, efforts should be made instead to exploit such information through the combination with some (weakly) rational forecasts. As shown, this is the case with the multiperiod survey forecasts of business investment collected from a panel of professional forecasters. 


\section{Suggestions for Future Research}

Beside from the univariate model, one may also utilize the accelerator, neoclassical, cash flow, and the q model for forecasting the future course of business investment. Since these models stress different factors to explain the behavior of such spending, there may be a good possibility that their forecasts contain distinct predictive information. If this proves to be the case, then combining may offer even further improvements in forecasting capital investment by businesses.

\section{Footnotes}

1. The authors would like to thank Dean Croushore of the Federal Reserve Bank of Philadelphia for supplying the survey data.

2. This follows the fact that the survey participants are provided with the previous quarter's preliminary data available at the time of survey.

3. Based on the augmented Dickey-Fuller (ADF) tests (Dickey and Fuller, 1979) with the critical values from MacKinnon (1991), It is found to be integrated of order one for the 1962.1-1981.3 sample period.

That is, the ADF test statistic is 1.73 for It and 3.48 for $\Delta \mathrm{It}$ with eight augmented lags included in the ADF test equations. The adequacy of the augmented lags is checked with tests for serial correlation using the Ljung-Box Q-statistics. The $\mathrm{ADF}$ equation for the test on the levels includes an intercept and time trend term, to allow a deterministic trend under the alternative. In testing for a unit root in the first differences, only the intercept is included.

4. The first-revised data for the immediately preceding quarter, It-1, will be available just after respondents mail back the questionnaire.

5. For example, the number of respondents fell from 40 to only 9 in the summer of 1990 when the survey was taken over by the research department of the Federal Re- serve Bank of Philadelphia.

6. These findings are generally consistent with the results reported by Baghestani and Kianian (1993) on Business investment. More specifically, measuring the actual series by the preliminary data, Baghestani and Kianian show that the multiperiod forecasts of business investment all fail to be unbiased for 1981:31991:2 sample period. Their study, however, does not go far enough to examine the predictive information content of business investment forecasts.

\section{References}

1. Baghestani, Hamid, and Amin M. Kianian, "On the Rationality of US Macroeconomic Forecasts: Evidence from a Panel of Professional Forecasters," $A p$ plied Economics, Vol. 25, pp. 869-878, 1993.

2. Dickey, David A. and Wayne A. Fuller, "Distribution of the Estimator for Autoregressive Time Series with a Unit Root," Journal of the American Statistical Association, Vol. 74, pp. 427-31, 1979.

3. Fair, Ray C. and Robert J. Shiller, "The Informational Content of Ex Ante Forecasts," Review of Economics and Statistics, Vol. 71, pp. 325-331, 1989.

4. Fair, Ray C. and Robert J. Shiller, "Comparing Information in Forecasts from Econometric Models," American Economic Review, Vol. 80, pp. 375-389, 1990.

5. Granger, Clive W. J. and Ramu Ramanathan, "Improved Methods of Combining Forecasts," Journal of Forecasting, Vol. 3, pp. 197-204, 1984.

6. Hafer, R. W. and S. E. Hein, "On the Accuracy of Time Series, Interest Rate, and Survey Forecasts of Inflation," Journal of Business, Vol. 58, pp. 377-98, 1985.

7. Keane, Michael P. and Daniel L. Runkle, "Testing the Rationality of Price Forecasts: New Evidence from Panel Data," 
American Economic Review, Vol. 80, pp. Notes 714-35, 1990.

8. Kopcke, Richard W. "The Determinants of Business Investment: Has Capital Spending Been Surprisingly Low?" New England Economic Review, Federal Reserve Bank of Boston, (Jan./Feb.), pp. 331, 1993.

9. MacKinnon, James G. "Critical Values for Cointegration Tests," in Long-run Economic Relationships, edited by Robert F. Engle and Clive W.J. Granger, Oxford: Oxford Press, pp. 267-276, 1991.

10. Pearce, Douglas K. "Comparing Survey and Rational Measures of Expected Inflation: Forecast Performance and Interest Rate Effects, Journal of Money, Credit, and Banking, Vol. 11, pp. 447-456, 1979.

11. White, Halbert. "A Heteroskedasticity Consistent Covariance Matrix Estimator and a Direct Test for Heteroskedasticity," Econometrica, Vol. 48, pp. 817-838, 1980.

12. Zarnowitz, Victor. "Rational Expectations and Macroeconomic Forecasts," Journal of Business and Economic Statistics, Vol. 3, pp. 293-311, 1985. 
Notes 